\title{
REDES SOCIAIS COMO NOVO MARCO INTERPRETATIVO DAS MOBILIZAÇÕES COLETIVAS CONTEMPORÂNEAS
}

\author{
Paulo Henrique Martins"
}

\begin{abstract}
Os rumos dos movimentos sociais e das mobilizações sociais e culturais na contemporaneidade assinalam o enfraquecimento dos antigos marcos teóricos positivistas que subordinavam a constituição das práticas identitárias a certos critérios reducionistas, como o do utilitarismo econômico e o da ideologia do progresso. No entanto, as mudanças recentes produzidas pelos processos de desterritorialização e reterritorialização nas sociedades complexas impõem novos tipos de atores, conflitos e mediações, sendo as redes uma forma social exemplar dessas mudanças. Mas as redes não se impõem automaticamente como um novo marco interpretativo. É importante explicar que elas são objeto de embate no campo intelectual e que podem conhecer leituras diversas, tanto utilitaristas como antiutilitaristas.

PALAVRAS-CHAVE: redes sociais, movimentos sociais, utilitarismo, teoria sociológica.
\end{abstract}

\section{INTRODUÇÃO}

Os rumos dos movimentos e mobilizações sociais e culturais na contemporaneidade assinalam a debilitação dos antigos marcos teóricos positivistas que subordinavam a constituição das práticas identitárias a certos conteúdos substantivos, como o da economia, que continua a ser particularmente valorizado. Contudo, as mudanças recentes produzidas pelos processos de desterritorialização e reterritorialização nas sociedades complexas (Mato, 2007) impõem novos tipos de atores, de conflitos e de mediações, o que contribui para demonstrar que a constituição da identidade social, coletiva e individual conhece influências mais amplas do que as referências substantivas e reducionistas. Os conflitos ultrapassam as esferas sociais, políticas e econômicas e incluem esferas culturais e simbólicas, dando profundidade às lutas por reconhecimento. Para $\mathrm{H}$.

* Professor Titular da Universidade Federal de PernambucoUFPE. Doutor em Sociologia. Pesquisador I do CNPq coordenador do Nucleo de Cidadania (NUCEM) da UFPE. Rua Acadêmico Hélio Ramos s/n Cidade Universitária. Cep: 50679-900 - Recife - Pernambuco - Brasil. pahem@terra.com.br
Bhabha, o teoricamente inovador e politicamente crucial é a necessidade de passar das narrativas originais e singulares (como as de classe e gênero) para integrar novas subjetividades produzidas na articulação das diferenças culturais, exemplificadas pelas novas orientações sexuais, as novas mobilizações étnicas e feministas, dentre outras (Bhabha, 2003, p.19-20).

Essas mudanças teóricas e práticas assinaladas são importantes, pois mostram que os movimentos sociais vivem, na atualidade, um processo de diferenciação e de deslocamento decisivo, com outras modalidades de mobilizações. Tais mobilizações escapam das formas tradicionais de articulação política, devido ao surgimento de unidades diversificadas e autônomas que dedicam à solidariedade interna uma parte importante de seus recursos (Melluci, 2001, p. 95). Isso nos conduz a redefinir os movimentos, nas sociedades complexas, como redes invisíveis de grupos, de pontos de encontro, de "circuitos de solidariedade, que diferem profundamente da imagem do ator coletivo politicamente organizado" (Melluci, 2001, p.97). Essas mudanças históricas e sociológicas gerais 
tornam evidente, então, que estamos vivendo a emergência de um novo paradigma sociológico, ${ }^{1}$ necessário para explicar a passagem dos movimentos sociais da sociedade moderna para novos movimentos sociais das sociedades complexas contemporâneas. ${ }^{2}$ Esse novo paradigma ganhou visibilidade pelo reconhecimento da presença inquestionável de pequenos sistemas dinâmicos, denominados redes sociais, que funcionam como novos aparelhos reguladores dos conflitos, tensões e acordos entre indivíduos e grupos minoritários.

A emergência dessenovo marco interpretativo ocorre, de maneira geral, pela superação do tradicional paradigma holista - que valoriza a totalidade social e descuida do indivíduo - e do paradigma individualista - que faz o contrário. Para Alain Caillé, o paradigma emergente é o do dom, ${ }^{3}$ e sua presença se torna cada vez mais visível nos diver-

${ }^{1}$ Segundo T. Kuhn, a ciência não se desenvolve conforme uma lógica de progresso contínuo, mas conforme aquilo que constitui, num momento dado, uma ciência normal e legítima. Logo, são reconhecidas como legítimas e aceitáveis as teses inscritas na ciência "normal" de uma época, a saber, o paradigma dominante (Kuhn, 1975). Kuhn não logra, para Alain Caillé, avançar para uma definição precisa do que é um paradigma e, nas ciência sociais particularmente, nos lembra Caillé, não se pode falar de um só paradigma, senão de dois: o individualista e o holista. Nesse sentido, ele propõe, no caso das ciências sociais, que é melhor definir a ideia de paradigma "como um conjunto de teorias e modelos de explicação reconhecidos pelas comunidades pesquisadoras e que define o campo do pensável e dos questionamentos legítimos." (Caillé, 2000, p. 13)

2 Junto aos antigos atores coletivos, as sociedades contemporâneas incluem também os indivíduos como novos atores decisivos para sua existência. Como nos lembra A. Melluci, a intervenção da sociedade se dá no sistema em seu conjunto, mas também nos indivíduos singulares, "em sua capacidade simbólica individual, as possibilidades de cada um de definir o sentido de sua própria ação.” (Melluci, 2001, p. 71). De acordo com o esclarecido por Arnold-Chatalifaud, Thumala e Urquiza (2007), essas novas formas sociais individuais não devem ser avaliadas negativamente; ao contrário, é importante compreendê-las como signos de novas formas de solidariedade, como fundamentos de experiências inéditas de colaboração coletiva, fundadas na individualidade e na contingência (p.22).

${ }^{3} \mathrm{O}$ dom é um modelo de ação social revelado por Marcel Mauss em seus Ensaios sobre o dom, de 1924 (Mauss, 2003), nos quais busca demonstrar que, em todas as sociedades já existentes, ocorre um sistema de troca generalizado, de doação, de recepção e de retribuição de ben simbólicos e materiais, inclusive em certas sociedades primitivas que não conheciam o Estado e o mercado. O dom é um modelo triádico da ação social, que integra, na sua compreensão, não só as descrições das práticas dos agentes, mas, sobretudo, as funções simbólicas que dão sentido a tais práticas. Para quem não conhece a discussão sobre o dom, há um livro em português de Jacque Godbout intitulado O espírito da dádiva (1999) que constitui uma boa apresentação dessa rica discussão teórica. sos domínios da vida social e cultural, sendo exemplificado pelas novas formas de solidariedade em diversas esferas da vida cotidiana, como as da economia e a família, da política e a comunidade. Como o dom é, por sua natureza, o que permite superar a antítese entre o eu e o outro, entre obrigação e liberdade, compreende-se facilmente que

pensar de acordo com o dom implica aprender a superar a tensão não-resolvida entre os dois grandes paradigmas, nos quais se dividem as ciências sociais e boa parte da filosofia moral e política, dada a necessidade de resolver essas oposições. (Caillé, 2000, p. 12).

Podemos propor que a mudança de paradigma nas teorias dos movimentos sociais se dê pela superação das teses holísticas - que reduzem os movimentos a mudanças estruturais gerais, tal e como o fez o marxismo com sua teoria do movimento operário - e das teses individualistas - que reduzem a mudança social a um jogo de estratégias individualistas ou de pequenos grupos pelo controle dos recursos coletivos, que chamam, em geral, de "capital social”.

A tese central deste texto é que a emergência do novo paradigma dos movimentos sociais se verifica pela força crescente da ideia de rede social no interior das ciências sociais, como respostas às mudanças sociais e históricas gerais. Contudo, entendemos que o reconhecimento mais amplo desse novo paradigma é impedido pela presença de estratégias de colonização e de naturalização das teorias das redes e por meio de teses utilitaristas que buscam reduzir toda a ação coletiva e individual a motivações egoístas e interessadas, como o fazem as teorias da "rational choice". As tentativas de colonização das teorias de redes têm um objetivo mais profundo: o de impedir que a ciência reconheça mais claramente a importância das mudanças históricas geradas pelas identidades sociais e culturais emergentes. Essas, contudo, são, por sua natureza, um testemunho decisivo contra as teorias individualistas, reducionistas e autorreferenciais, que discutem a força da mudança histórica das coletividades humanas na contemporaneidade. Assim, o objetivo central deste artigo é desenvolver 
uma crítica teórica ao colonialismo que incide sobre a teoria das redes, com a finalidade de facilitar a sistematização desse novo paradigma sociológico, baseado na diferenciação, na presença confluente de grupos e indivíduos e na força das minorias que lutam por novas solidariedades e reconhecimentos.

\section{REDES SOCIAIS: usos gerais e recepção na sociologia}

\section{O problema da naturalização da noção de redes sociais}

A discussão em torno da pergunta se existe uma sociologia das redes sociais e se ela aponta para um novo paradigma sociológico não é recente. Já nos anos setenta, S. Leinhardt (1977) propunha que os estudos sobre redes apontavam para um novo paradigma. Todavia esse debate não avançou muito desde então. Silvia Portugal, pensando especificamente sobre o caso do network analysis, propõe que, no sentido kuhniano, falta a esse modelo de análise a força que teve o funcionalismo como movimento paradigmático. Assim, Portugal conclui que, devido à distância em que se encontra o campo interno da disciplina de constituir-se como teoria unificada, não se pode falar da emergência de um novo paradigma (Portugal, 2007, p. 9).

Apesar de concordarmos com a autora no que diz respeito, especificamente, ao fato de que o network analysis não constitua a base de um novo campo de pensamento, acreditamos que a questão continua aberta e que é possível defender a perspectiva das redes sociais com base em um novo paradigma sociológico. Para isso, contudo, temos de considerar dois pontos. Um deles tem a ver com o fato de que a teoria social das redes constitui um domínio de reflexão muito mais amplo que o do network analysis, que é apenas um procedimento técnico e prático usado pelas teorias utilitaristas para colonizar a realidade social, como veremos mais adiante. Em segundo lugar, temos de considerar, na discussão sobre o tema no interior das ciências sociais e da sociologia, uma espé- cie de naturalização da noção de redes sociais que impede o desenvolvimento de uma compreensão mais profunda do fenômeno. Isto é, um entendimento reflexivo que permita explicitar os fundamentos normativos e expressivos das mudanças sócio-históricas que estão na base da manifestação fenomênica das redes a partir da segunda metade do século XX. A questão da naturalização no campo científico tem a ver com o processo de transformação de dogmas históricos e culturais em crenças metafísicas. No desenvolvimento da ciência moderna, o principal processo de naturalização se deu a partir do culto a uma interpretação etnocêntrica do mundo - cuja referência é Descartes - , segundo a qual a natureza se divide em duas partes irreconciliáveis: por um lado, a natureza iluminada pela razão humana; por outro, a natureza caótica e irracional do mundo no humano. Grande parte do trabalho da filosofia moderna do século XX foi o de desconstruir esse entendimento etnocêntrico. ${ }^{4}$

A naturalização das redes no interior do campo humanista se realizou com duas estratégias: uma delas ao importar o termo dos campos discursivos de outras ciências, como a engenharia, sem proceder a uma crítica mais sistemática da operação de tradução teórica; ${ }^{5}$ a segunda foi a de

${ }^{4} \mathrm{Um}$ dos pontos fortes da crítica moderna foi dado por M. Merleau-Ponty, com seu célebre Fenomenologia da percepção, editado pela primeira vez em 1945. Em uma entrevista à Rádio Nacional Francesa, em 1958, criticando o modo como Descartes opera a separação metodológica entre os homens e as coisas, o autor declara que Descartes "Não via no animal mais do que uma súmula de rodas, alavancas, molas, enfim, uma máquina..." (Merleau-Ponty, 2004, p. 27). E, no esforço para desconstruir essa leitura objetivista do mundo, propõe que o ser humano desperte para o mundo percebido, redescobrindo, em cada coisa, "certo estilo de ser que a torne um espelho das condutas humanas...". Mais adiante, nos anos 60, M. Foucault estende a crítica desconstrucionista, demonstrando que todo conhecimento objetivado - ou meramente subjetivado - é falso, sendo a realidade, inclusive a das instituicões sociais, feita de formações discursivas (Foucault, 2007). A enunciação da desconstrução como método científico avança com os pós-estruturalistas. Ela tem em J. Derrida uma referência importante, sobretudo no campo linguístico (Derrida, 1967) e, na atualidade, esse método foi utilizado com muita pertinência e profundidade por C. Taylor (2005) para revelar as hierarquias morais ocultas no processo de construção do self na modernidade. Por fim, na desconstrução, há de se considerar que os saberes científicos em ciências sociais não são cumulativos (Osório, 2007, p. 9) e que há uma relação estreita entre o conhecimento (desconstruído) e os processos de emancipação (Scribano, 2008).

${ }^{5}$ No campo da ciência propriamente dito, seja entre as ciências "exatas" ou entre as ciências sociais, o termo 
adotar um sentido utilitarista de rede nas ciências sociais, sem considerar que a complexidade da realidade histórica exige a integração de um novo marco interpretativo que amplia as motivações dos indivíduos pela associação e solidariedade coletiva, para além do simples lucro. Quanto à primeira estratégia, deve ser assinalado que, com frequência, os pesquisadores sociais se servem da ideia de rede para definir, sem maiores questionamentos, todo sistema formado pelo entrelaçamento de informações técnicas entre indivíduos e grupos sociais. Pode-se dizer, inclusive, que seu uso na engenharia de sistemas marcou sua difusão no sentido comum e, como desdobramento, no campo das ciências sociais. A partir dessa perspectiva, a rede social obedeceria à mesma lógica que todas as outras noções correntes de redes nos diversos campos do conhecimento e da vida cotidiana (rede óptica, rede de arrasto, rede neural, rede elétrica, rede de espionagem, entre outras). Na sociedade, apareceria, por acaso, como propõe E. Mance (2001), sob a forma de ideia simples, ou seja, uma ideia autoevidente, de uso funcional. Contudo, tal afirmação sobre a simplicidade das redes, como veremos, não é nada simples. A simplicidade é apenas um efeito de óptica, que emerge a partir da adoção de uma forma de interpretação funcionalista simplificada das redes, que contribui para camuflar a complexidade das novas formas de mobilizações coletivas da sociedade contemporânea. ${ }^{6}$

No que diz respeito à segunda estratégia, a de naturalização da noção de rede social produzida pela integração do sentido utilitarista de rede nas ciências sociais, observamos que aqui ocorre a identificação do sentido de rede com uma ideia de

conhece interpretações múltiplas e comunicantes entre si. Isso é uma chave para aqueles que se ocupam da engenharia de transportes, de sistemas de redes elétricas e fisiológicas ou de gestão estratégica (redes de hospitais, redes de escolas, etc.). Os usos práticos da rede por engenheiros e gestores privados e públicos têm eficácia inquestionável em certos campos do conhecimento, particularmente na gestão e monitoramento de informações

${ }^{6} \mathrm{E}$ Mance afirma que "A ideia elementar de rede é bastante simples. Trata-se de uma articulação entre diversas unidades que, por meio de certas conexões, intercambiam elementos entre si, fortalecendo-se reciprocamente, e que podem se multiplicar em novas unidades. Cada nó de redes representa uma unidade e cada fio um canal por onde essas unidades se articulam através de diversos fluxos (Mance, 2001, p. 24) lucro material generalizado. Ou seja, o sentido utilitarista de rede está muito influenciado pela valorização de uma moral do comportamento humano baseada no cálculo e no interesse, que não considera outra compreensão mais solidária, generosa e humanista do fenômeno. ${ }^{7}$ Este segundo modo de naturalização da noção de rede nos parece mais grave, já que contribui para uma crescente desumanização das práticas sociais. Ao hipervalorar a competência egoísta e a privatização de riquezas materiais e simbólicas coletivas por indivíduos ou grupos, tal abordagem não estimula outros entendimentos que ressaltam a força da cooperação e da solidariedade social na organização de novas mobilizações coletivas. Nas ciências sociais, abordagens como a do individualismo metodológico, a "rational choice" e a análise institucionalista tendem a incorporar a moral utilitarista na análise social de redes. No nosso entender, como tentaremos demonstrar neste artigo, tais teorias são veículos poderosos para a colonização do mundo das redes sociais comunitárias por parte do sistema de pensamento dominante, mais conhecido como neoliberalismo.

Os prejuízos provocados pelas dificuldades de as redes sociais se estabelecerem como um novo marco teórico são revelados principalmente "pela negligência com" os fundamentos sócio-históricos das redes sociais na contemporaneidade, consequência da perpetuação dos mecanismos de neutralização dessa noção. E também pela influ-

O utilitarismo, segundo os filósofos mercantilistas ingleses J. Bentham e J. S. Mill, é a doutrina segundo a qual os sujeitos humanos são regidos pela lógica do egoísmo e do cálculo permanente de seus prazeres e sofrimentos, ou de seus lucros e perdas. Segundo A. Caillé, na modernidade, o utilitarismo já não corresponde mais a um sistema filosófico particular ou a um componente, entre outros, do imaginário dominante das sociedades modernas, mas ao próprio imaginário moderno. "De tal modo que, para os modernos em geral, o que não seja traduzível em termos de utilidade e eficácia instrumental não tem sentido" (Caillé, 1989, p. 9). A crítica ao utilitarismo é a própria essência do Movimento Antiutilitarista das Ciências Sociais (M.A.U.S.S.), fundado na França em 1981 e que edita a Revue Du Mauss. A crítica antiutilitarista tem dois momentos importantes: a crítica difusa, própria dos anos oitenta, e a crítica propositiva, que tende a colocar o dom como um paradigma antiutilitarista alternativo nas ciências sociais, que ganha espaço a partir dos anos noventa, por meio de autores diversos, como o próprio Caillé, mas também como o sociólogo canadense J. Godbout, uma referência entre os especialistas do dom, mas ainda pouco conhecido na América Latina, entre outros. 
ência de uma visão ideológica utilitarista, que reduz a complexidade dos motivos da prática social em redes a um valor moral egoísta e calculista. Esse declínio leva os estudiosos de rede, em geral, a esquecer algo que Melluci (2001) já havia explicado com clareza, mas que parece não ter sido devidamente registrado numa perspectiva integral, a saber, que existe uma relação estreita das redes com as novas manifestações socioculturais e com os desdobramentos dos movimentos sociais nas sociedades complexas. ${ }^{8}$ Queremos destacar a ideia de entendimento integral para chamar a atenção sobre o fato de que a legitimação das redes sociais, como um novo paradigma sociológico, exige discutir a coerência entre as novas teses teóricas e a complexidade crescente da realidade sócio-histórica, que já não pode ser explicada nem pelos paradigmas tradicionais holistas - que identificam o movimento social com totalidades identitárias da classe operária -, nem pelos individualistas que identificam o movimento social com as estratégias individualistas, como o fazem as teorias colonizadoras que estamos interrogando neste texto.

As evidências no cotidiano constituem um bom ponto de partida para que retomemos os caminhos de uma reflexão mais profunda sobre o tema. É evidente, por exemplo, o aumento do prestígio que as redes sociais vêm ganhando entre os interessados nos debates sociológicos. ${ }^{9}$ Elas despertam um sentimento de emergência entre os que estudam a emancipação da sociedade civil, a gestão social solidária e a democracia participativa. As redes também atraem o interesse crescente dos

${ }^{8}$ A. Melluci nos lembra que as mobilizações coletivas vêm assumindo formas organizativas que escapam das categorias da tradição política, pois são marcadas por "unidades diversificadas e autônomas que dedicam à solidariedade interna uma parte importante de seus recursos.” (Melluci, 2001, p. 95). Por sua parte, T. Villasante esclarece que estamos passando de uma fase de sociedade complexa, marcada pelo movimento comunitário, para outra caracterizada por "vários movimentos cidadãos". Pelo fato de as identidades sociais estarem fraturadas por motivos diversos - medos, condicionantes de classe, degradação do ecossistema etc. - torna-se decisivo compreender as relações internas dos sujeitos. Que são rizomáticas, múltiplas, fraturadas e fractais, influindo sobre os estilos, condutas e ideologias (Villasante, 2002, p. 38).

${ }^{9} \mathrm{Na}$ Espanha, edita-se uma revista virtual muito importante intitulada REDES - Revista hispânica para a análise de redes sociais (http:|revista-redes.rediris/es); ao leitor interessado que deseje confirmar nossas observações sugerimos visitar o sítio da revista. investigadores e dos editores de livros acadêmicos. A ideia de uma sociologia relacional fundamentada em redes é estimulante para aqueles que desejam superar o dilema sociológico clássico entre estrutura e agência. Mas esse interesse teóricoprático pelo tema das redes vem sendo neutralizado progressivamente por abordagens que não valorizam a atualidade sócio-histórica e normativa do fenômeno. Daí a existência atualmente de um processo intelectual orientado para o declínio de seu caráter fenomênico e hermenêutico, ao mesmo tempo em que se reforça sua interpretação utilitarista e formalista, o que, sem dúvida alguma, interfere negativamente no entendimento do caráter relacional das redes sociais. Finalmente, essas diferentes leituras das redes nas ciências sociais não contribuem, por conseguinte, para valorizar o caráter inovador da rede como marco interpretativo das novas mobilizações sociais e culturais.

Entretanto, acreditamos que o fato de se reconhecer a existência de uma produção múltipla, inclusive caótica, não deve ser visto como um impedimento estrutural para os esforços de sistematização de uma sociologia das redes sociais que faça avançar concretamente o entendimento das novas mobilizações coletivas em mundos territorializados. Nesse sentido, pensamos que é possível avançar, desde que sejamos capazes de indicar os aspectos que bloqueiam a discussão. Entre eles, como procuramos demonstrar, encontram-se, em primeiro lugar, aqueles estudos que destacam o declínio dos fundamentos discursivos, sócio-históricos e morais, do fenômeno das redes.

\section{Uma primeira e provisória tentativa de classi- ficar a abundância caótica de estudos sobre redes sociais}

Ao analisar a produção acadêmica sobre essa temática no campo discursivo ibero-latino-americano, percebem-se alguns traços significativos: a) existe uma produção muito rica e diversificada sobre redes sociais; b) apesar dessa riqueza diversificada, a produção se mostra fragmentada, 
como um pensamento abundante e caótico, que impede valorar corretamente os avanços efetivos nos estudos da área. Nesse sentido, Portugal tem razão ao afirmar que a multiplicidade de perspectivas diferenciadas impediria a identificação de um novo paradigma dominante (Portugal, 2007).

Para que possamos desconstruir tal visão naturalizada das redes e fazer a crítica correta do sujeito rede, temos de procurar oferecer um mínimo de organização a esse conjunto amplo e diversificado de textos sobre o tema que apontam, em conjunto, para uma direção clara, aquela que busca construir teorias mais complexas para explicar a crescente diferenciação social. Tal empresa, certamente, não pode ter pleno êxito dentro dos limites de um artigo como este. Mas os esforços de organizar minimamente o campo discursivo exigem avançar na crítica teórica. Em primeiro lugar, temos de discutir o critério adequado para promover a organização do conjunto diversificado e caótico de estudos sobre o tema. E o critério que consideramos apropriado para tal operação classificatória tem de ser necessariamente o da possibilidade de visualizar os níveis de desconstrução das noções naturalizadas de redes sociais, tendo como ponto de partida o mais simples, isto é, as noções menos elaboradas do ponto de vista da discursividade. Com essa classificação, acreditamos ser possível organizar provisoriamente a critica antiutilitarista do modelo hegemônico que vem influindo na qualidade da produção teórica sobre redes, demonstrando também que a presença do utilitarismo não revela apenas uma luta por significações dentro do campo científico, mas manifesta igualmente a presença de um pensamento hegemônico e autoritário que vincula a ciência com o imaginário do neoliberalismo.

Desde já, podemos propor, preliminarmente, que a produção ibero-latino-americana tende a se localizar em dois níveis de interpretação de redes que, como demonstraremos, são ambos insuficientes por não produzirem uma visão integral do fenômeno. Há um primeiro grupo de autores que reproduzem, de certo modo, o sentido comum, ou seja, que consideram a rede como algo simples: "uma articulação entre diversas unidades que, por meio de certas conexões, intercambiam elementos entre si, fortalecendo-se reciprocamente e que podem se multiplicar em novas unidades (Mance, 2001, p. 24). Nessa perspectiva, a ideia de redes não conhece maior elaboração teórica, e se faz referência a elas principalmente pela sua força metafórica, sem uma preocupação em aprofundar suas dimensões históricas, culturais e simbólicas. Nesse grupo estão aqueles que aplicam a noção para descrever antigos e novos arranjos de poder (AdlerLomintz, 1994; Macías, 2002); também aqueles que consideram a rede como um recurso a priori para descrever as novas mobilizações sociais e práticas cotidianas (Alonso Davila, 1992; Requena Santos, 1994; Mance, 2001; Mariadaga; Abello Llanos; Cierra García, 2005); e os que usam a noção de redes para explicar as transformações das organizações e do mundo do trabalho (Requena Santos, 1991; Rodrigues, 1995; Molina 1995).É possível prolongar essa classificação para incluir os estudos sobre gênero, etnia, violência, entre outros.

O segundo grupo de autores, diferentemente do primeiro, não usa a ideia de rede apenas como metáfora, mas busca teorizá-la com a finalidade de intervir na realidade social. Nesse caso, a ideia de rede se abre mais claramente para a inclusão de sistemas funcionais articulados por indivíduos e agências humanas, e os estudos teóricos tendem a se inspirar em duas grandes linhas de pensamento. Uma delas, que podemos denominar como técnico-pragmática (pragmatismo no sentido comum, não filosófico), inclui os autores que veem esses intercâmbios como redes sociotécnicas (Callon, 1989; Musso, 2003; Latour, 2005; Castells, 2007). A outra linha, que podemos denominar como utilitarismo individualista, abarca aqueles defensores da network analysis, para os quais as redes são modalidades de mobilização causal de recursos e informações que envolvem indivíduos autônomos - autonomia radical ou parcialmente condicionada por estruturas - em torno de objetivos estratégicos e interessados (Granovetter, 1983; Bourdieu, 1999; Coleman, 1990; Lin, 2001; Putnam, 2002). As teorias sobre o capital social, o individualismo metodológico e o "rational choice", 
em uso nos estudos de rede na América Latina, se apoiam, em geral, nessa visão mais propriamente utilitarista das redes.

Dependendo do caso, aqui a noção de recursos estratégicos adquire a denominação de capital social, ou de cultura cívica. Esse segundo módulo de saberes e práticas teve uma ampla aceitação entre aqueles autores de língua portuguesa que se interessam pelas políticas públicas e por novas modalidades de gestão do Estado e do território geossocial. No Brasil, em particular, é significativo o número de autores que utilizam a noção de redes sociais com esse fim de planificação e intervenção, como, por exemplo, Abramovay (2000) na agricultura, Marques (2002) nas políticas de saneamento urbano, Fontes (2004) no terceiro setor e Fleury e Duverney (2007) ${ }^{10}$ nas políticas de saúde. Dentro da produção em língua espanhola, há uma maior preocupação com a difusão de textos diversos sobre as questões teóricas e metodológicas resultantes da abordagem utilitarista e individualista de redes, como vemos em Canals (1991), que tem interesse nos conceitos operatórios, Herrero (2000) com problemas de definição e tradução, Pizarro (2000) e Gil (2002) com os usos de rede.

Essa primeira aproximação ainda imprecisa é, contudo, importante para revelar o interesse que o tema das redes vem despertando no interior das ciências sociais. Isto é, o fenômeno da rede tem claramente uma aceitação ampla e crescente no mundo acadêmico e vem conhecendo, como tentamos demonstrar aqui, uma teorização de certo modo limitada pela força das argumentações utilitaristas no campo humanista.

\section{Algumas considerações iniciais sobre a críti- ca antiutilitarista das redes sociais}

Para que possamos desenvolver uma crítica antiutilitarista das redes sociais, de modo a contri-

${ }^{10}$ S. Fleury e A. M. Duverney (2007, p. 9-10), por exemplo, desenvolvem a noção de "redes de políticas" para designar as novas estruturas organizacionais policêntricas que revelam uma maior complexidade dos processos administrativos nascidos dos processos de descentralização da área de saúde no Brasil. buir para desnaturalizar os usos correntes e superficiais dominante, temos de centrar nosso enfoque no entendimento das redes que promova a dupla hermenêutica lembrada por B. S. Santos, aquela da suspeita e da recuperação, pela qual não podemos compreender as partes sem entender como "trabalha" o todo e vice-versa (Santos, 1989, p. 11-12). Tais atitudes de suspeita e recuperação podem ser visualizadas em dois níveis de complexidade teórica: entre o subjetivo e o objetivo, entre o saber científico e o saber comum. Uma abordagem racional e dialógica, que atenda a tais requisitos paradigmáticos, deve ser capaz de articular os motivos e condicionantes intersubjetivos dos sistemas de relação com as modalidades objetivas de aparição das formas sociais, procurando demonstrar que o plano objetivo está condicionado pelo subjetivo, como a água, por exemplo, está condicionada pelas moléculas de oxigênio e hidrogênio que a constituem objetivamente como substância líquida.

A abordagem interacionista que pretendemos desenvolver neste texto, que valoriza uma perspectiva antiutilitarista, ou seja, aberta à articulação do objetivo e do subjetivo, resulta de uma série de estudos que avançam nessa direção, feitos de forma explícita mas tradicionalmente de modo discreto por autores como Simmel (1999) e Mauss (2003), e de forma declarada por autores como Elias (1994) e Melluci (2001). Esse último enfatiza o valor da qualidade dos intercâmbios, não para negar o interesse das operações de base quantitativa, mas para evidenciar a força do simbolismo e da diversidade de possibilidades intersubjetivas de constituição da realidade social. ${ }^{11}$ Não se trata, deve-se esclarecer, de estabelecer uma bipolaridade entre rede objetivada e rede subjetivada, mas de superar tal dilema - que é falso - para propor uma visão de redes sociais que responda hermeneuticamente aos princípios da interação e da reciprocidade.

${ }^{11}$ Particularmente, acreditamos que a teoria da dádiva tem um papel importante para avançar nessa ruptura epistemológica, permitindo-nos entender os fatores de complexidade, normatividade e reflexividade das práticas sociais a partir de uma perspectiva antiutilitarista. Num texto anterior, no qual tratamos dessa discussão, propusemos que as estruturas simbólicas e paradoxais do dom e da reciprocidade (Martins, 2004) são instituintes com relação às estruturas funcionais e cognitivas objetivadas das relações sociais. 
Trata-se de abrir a concepção de rede para um entendimento complexo que articula o instituído e o instituinte, valorizando a influência do simbolismo sobre as práticas objetivadas. Tal enriquecimento conceitual do uso sociológico de redes, a partir da consideração dos elementos intersubjetivos, permite estabelecer as bases para a crítica teórica do pensamento monolítico dominante. Essa crítica busca demonstrar que tal pensamento é reducionista por articular um entendimento fragmentado, funcionalista e individualista da realidade social. E essa fragmentação tem um desvio ideológico por induzir uma leitura simplificada da prática social e um pensamento único e utilitarista sobre as redes. Os resultados dessa crítica são o reconhecimento da diversidade de possibilidades de organizações em redes, que podem surgir em vários contextos sociais, históricos e culturais, a partir de lógicas diversas, causais e não-causais, contínuas, mas também descontínuas, visíveis e invisíveis, lineares e reticulares.

Diferentemente das teorias utilitaristas, formadas por conjuntos de saberes e práticas que são sistemas relativamente fechados, monitorados e organizados a partir de uma lógica de causalidades mecânica e (ou) funcional, as teorias de redes interativas, na perspectiva antiutilitarista, pressupõem a presença de sistemas paradoxais e abertos ao diálogo com outros sistemas interativos (dimensão hermenêutica), a vivência dos atores sociais (dimensão fenomenológica) e as obrigações coletivas que nascem da dívida simbólica entre indivíduos e grupos (dimensão da dádiva). O princípio do paradoxal, subjacente na visão interativa de redes, permite enfatizar as multideterminações do fato social, a variedade contraditória de motivações antropológicas que escapam a qualquer racionalidade instrumental, motivações que são, sobretudo, expressivas e dialógicas (Martins, 2004, p. 25). ${ }^{12}$

No plano das instituições humanas, há de se reconhecer que essa perspectiva antiutilitarista,

${ }^{12}$ No campo da política pública, no Brasil, essa terceira via teve grande aceitação entre os que estudam o fato associativo (Scheren-Warren, 2005; Gohn, 2003) e as ações públicas regidas pelo dom (Martins, 2006; Moreira, 2006; Lacerda; Pinheiro; Guizardi, 2006). aqui adotada, permite revelar o tema das redes sociais como se fossem a ponta de um iceberg, que nos mostra os sinais de uma grande modificação dos formatos de organizações tradicionais e o surgimento de formatos abertos a uma nova complexidade técnica, cognitiva, emocional e simbólica, que tem como pano de fundo a reconfiguração dos contextos onde se desenham as relações humanas. Os formatos tradicionais eram estruturas piramidais e centralizadas em núcleos de poder e de comando, relativamente centralizados e rígidos. Na modernidade, eles foram substituídos progressivamente por sistemas descentralizados e flexíveis como são as redes. ${ }^{13} \mathrm{E}$, na atualidade, podemos ver claramente que tal processo de diferenciação social, técnica e cultural está se aprofundando, exigindo novas mediações políticas culturais e organizacionais.

\section{DIFICULDADES DA SOCIOLOGIA DE REDES PARA FIXAR SEU PRÓPRIO CAMPO DE INVESTIGAÇÃO}

Na realidade, o desenvolvimento do campo de investigação científica próprio das redes sociais, em sociologia, apresenta de imediato, dois desafios que necessitam ser enfrentados: um conceitual, outro metodológico. O conceitual separa aqueles que entendem as redes sociais como fenômeno histórico, resultante da complexa diferenciação social e cultural das sociedades complexas daqueles que as veem como artifícios criados racionalmente por indivíduos para realizar certos objetivos pessoais ou de seu grupo de preferência. Esse segundo grupo se filia à tradição da filosofia utilitarista, segundo a qual todos os indivíduos são, por essência, egoístas, e o fim da vida social é

${ }^{13}$ Os sistemas tradicionais ainda subsistem, obviamente. Basta-nos ver os sistemas burocráticos centralizados dos Estados nacionais, a família patriarcal dominante em áreas rurais e urbanas ou as igrejas monoteístas fundadas, frequentemente, também sobre figuras poderosas. Mas essas formas organizacionais tradicionais vêm sendo revistas a partir de novos sistemas descentralizados, formados por núcleos autopoiéticos com comandos múltiplos e flexíveis, como se observa em empresas de software, quando pensamos em organizações privadas, ou então nas estruturas das ONGs e associações, quando pensamos nas organizações da sociedade civil. 
atender a essas demandas individuais ou de grupos de interesse. Esse é o pensamento hegemônico sobre redes. Quanto ao primeiro grupo, o daqueles que entendem as redes não como artifício, mas como fenômeno histórico, temos aqui uma herança antiutilitarista e humanista ampla, que define a rede a partir de uma pluralidade de motivações, entre as quais o interesse é apenas uma das razões que explicam por que as pessoas interagem e formam a vida social. Esse pensamento não é hegemônico, contudo, como veremos, ele oferece as condições teóricas e metodológicas reais para pensar as redes como possibilidade de renovação do paradigma sociológico.

O segundo eixo, o metodológico, é um desdobramento do primeiro eixo teórico. Aí, sim, as redes são meros artifícios, sua operacionalização depende quase exclusivamente de modelos matemáticos, que permitem a realização dos cálculos estratégicos dos atores envolvidos. Porém, no caso de se considerarem as redes como fenômenos históricos, então temos de ampliar tanto a compreensão do fenômeno rede - com a incorporação de abordagens fenomenológicas e hermenêuticas como o uso de outros métodos e técnicas que permitam ampliar a atenção do observador para a realidade estudada.

A atração crescente da ideia de redes sociais como categoria analítica na sociologia se justifica pela necessidade de explicações mais dinâmicas, fluidas e interativas, para dar conta da complexidade crescente das sociedades contemporâneas, tanto no plano macrossocial como no meso e microssocial. A importância do entendimento da sociedade contemporânea como um sistema complexo, aberto a múltiplos tipos de interação com os ambientes exteriores - movidos por pressões diversas resultantes de variados níveis de organização das ações sociais e regulados por mecanismos como os da democracia, dos movimentos sociais e culturais e pela economia de mercado-exige necessariamente novas modalidades de organização dos vínculos sociais como as das redes sociais.

\section{Um ponto de partida: o plano mesosociológico}

Para iniciar nossa discussão, temos de considerar um ponto de partida. Ele é dado ao constatar que a importância da discussão sobre redes, no interior do campo sociológico, emerge do reconhecimento da importância que tem a estruturação de uma subdisciplina sociológica voltada para o estudo do plano mesosociológico. ${ }^{14}$ Entretanto, diferentemente do que ocorre nas "ciências exatas", a aplicação prática da ideia de rede, nos estudos do social, ainda é problemática, sugerindo dificuldades importantes tanto no tratamento teórico como nas metodologias de abordagem da realidade social.

No âmbito do social, as teorias de redes surgem dos esforços para explicar formas mesosociológicas que não podem ser visualizadas a partir de abordagens macrossociológicas, delimitadas por grandes estruturas explicativas, nem a partir de planos microssociológicos, centrados apenas nas motivações individuais. A noção de rede emerge, por conseguinte, como base de uma sociologia mesosociológica indispensável para os que se preocupam em explicar os sistemas de relações humanas nos espaços do cotidiano, tendo como objeto de estudo grupos pequenos e medianos ou outros mais diversos, como redes de movimentos sociais, de estudantes, de escritores, de simpatizantes de um time de futebol, redes familiares, entre outros.

Na prática, contudo, há problemas diversos na aplicação das teorias correntes de redes nesse plano mesosociológico. Entre esses problemas, podem ser ressaltadas as dificuldades das aborda-

${ }^{14}$ Dois autores foram pioneiros em garantir o êxito essa empresa: um deles, J. Moreno, com a sociometria (Moreno, 1987); o outro, J. Barnes, com o estudo dos campos sociais originais (Barnes, 1954). A esse último é atribuído o mérito de ter utilizado, pela primeira vez, o termo "social network" nos anos 50. Contudo, os estudos sociométricos de Moreno já haviam sido sistematizados desde os anos 30, Também há de se ressaltar os estudos da antropóloga E. Bott, a primeira a demonstrar, mediante investigação empírica, que a dinâmica na família não depende apenas dos motivos dos indivíduos do grupo, mas também das relações que os membros estabelecem com outros, como parentes, amigos etc. (Bott, 1976). A partir desse momento, os estudos sobre redes sociais em sociologia passam a ser crescentemente reconhecidos pelo seu valor teórico e metodológico para estudar grupos pequenos e médios nas sociedades complexas. 
gens dominantes de redes para entender o caráter relacional propriamente dito da prática social em grupos. M. Granovetter percebeu isso ao nos lembrar que, apesar de a análise de redes dever permanecer à igual distância de concepções "sobressocializadas", como a do estrutural-funcionalismo de Parsons e de concepções "sub-socializadas" como a do "reducionismo psicológico de G. Homans, na prática, não é isso o que ocorre. Assim, ele nos recorda, as duas concepções criticadas compartilham uma mesma concepção atomizada da prática social, aquela de colocar em posição secundária a dimensão relacional. Segundo a concepção "sobressocializada", os indivíduos seriam atomizados pela submissão mecânica a normas exteriores; a "sub-socializada" vê os indivíduos atomizados por uma tradição utilitarista que reduz as motivações individuais a uma lógica de interesse mercantil (Granovetter, 2000, p.35). Mas a própria posição teórica de Granovetter a respeito desse problema epistemológico é discutível. Sua tese, por exemplo, sobre laços fortes e laços débeis, não parece escapar muito das abordagens "sub-socializadas”. E, contudo, se não se apoia nas teorias psicológicas de Homans ou de outros, acaba por adotar teorias racionalistas e funcionalistas que, no fundo, não são tão distantes das lógicas behavioristas de certas tendências da psicologia. Pois psicólogos motivacionais e sociólogos racionalistas tendem a circunscrever a ação humana a partir de mecanismos de causalidades de ação que são insuficientes para superar o dilema atual no uso das redes que o próprio Granovetter apontou.

Por conseguinte, apesar de a noção de redes constituir uma inovação sociológica inegável acreditamos que a discussão teórica vem seguindo rumos preocupantes, com desdobramentos ambivalentes que deixam ver a sombra do utilitarismo. Os que simpatizam com a abordagem estrutural tendem, de algum modo, a incorporar os esquemas de totalidade presentes nas obras de Durkheim e Parsons. Paralelamente, está aquele outro grupo de autores simpatizantes do individualismo racionalista, que são influenciados pelo funcionalismo sociológico e também pela psicolo- gia behaviorista. Esses valorizam mais os estudos sobre motivações individuais utilitaristas, ao acreditarem que às racionalidades dos atores se sobrepõem as ordens estruturais na formação de redes.

Contudo, tanto estruturalistas como individualistas têm dificuldades para compreender as práticas como articulação dinâmica do subjetivo com o objetivo, mediante construção de narrativas que envolvem diretamente os atores sociais. Nesse sentido, é importante assinalar os esforços daqueles que, influenciados pela antropologia britânica e autores como Wolfe (1978), insistem na possibilidade de separar-se das abordagens estruturalistas e individualistas para deter-se diretamente na análise das relações sociais concretas. Mas tais esforços oriundos da antropologia são limitados devido, sobretudo, às resistências tradicionais de sociólogos, formados na escola positivista, de integrar os elementos simbólicos e intersubjetivos da prática social.

\section{Utilitaristas e antiutilitaristas: lutas pelas sig- nificações das redes no interior do campo so- ciológico}

O surgimento de um pensamento hegemônico acerca de redes, marcado pela influência moral do utilitarismo, filosofia que elege o interesse egoísta como motivo supremo no momento em que os indivíduos decidem suas preferências no interior da sociedade, ${ }^{15}$ vem produzindo novas divisões entre os estudiosos de redes, reproduzindo uma disputa mais ampla no campo da sociologia (Martins, 2008). Os autores utilitaristas entendem a rede social como recurso estratégico e artificial, acionado por indivíduos e grupos com finalidades instrumentais e guiados por interesses

${ }^{15}$ Existe o utilitarismo filosófico, que elege o tema da utilidade a partir do interesse da maioria, o qual, segundo A Caillé, já estaria presente em Platão; existe o utilitarismo comum, ligados às preferências autocentradas dos indivíduos no dia a dia, e existe o individualismo mercantil, que floresceu na Inglaterra, sobretudo com os economistas como S. Mills e J. Bentham, e que constitui o centro do grande desenvolvimento atual das teses neoliberais e da defesa da autonomização do mercado com relação à política e à sociedade. 
racionalistas individuais e grupais. Essa orientação contribui para reforçar o pensamento monolítico dominante. No lado contrário, existe uma plêiade desorganizada de autores que intentam entender as redes não como instrumento, mas como um pressuposto sistêmico da vida social: a rede como condição significante para a existência de processos de diferenciação social próprios de sociedades complexas. Esses autores contribuem para o surgimento de pensamentos e saberes contrahegemônicos. Nesse caso, as redes são vistas como possibilidades fenomênicas e discursivas de emancipação de saberes e práticas que se encontram reprimidos e (ou) inibidos.

Para situar esse embate, podemos tomar como exemplo o caso das mudanças verificadas no campo biomédico na atualidade, a partir de pressões importantes exercidas por forças diversas: por um lado, o saber biocartesiano utilitarista, que se propõe como o único saber verdadeiro sobre a saúde; por outro lado, os diferentes saberes de cura já existentes, como a medicina doméstica e a medicina xamânica, construídos a partir de experiências vividas e reproduzidas pelas tradições e memórias que foram reprimidas e perseguidas durante muito tempo e que, inclusive, de forma desorganizada, vêm questionando o monopólio do saber médico pelo biocartesianismo da clínica médica (Martins, 2003). Essas mudanças, no interior do campo médico e em suas fronteiras, são reflexos de outras mudanças que vêm ocorrendo na vida social, tendo como uma de suas principais legitimações as novas redes interativas do cotidiano.

O fato de que as teorias hegemônicas sobre redes apenas entendam o lado objetivo e instituído da prática social, desestimulando a variedade de discursos possíveis na construção da realidade, como demonstraremos no curso do presente artigo, contribui decisivamente para as dificuldades de sistematização de teorias mais complexas sobre as redes sociais. Assim, de uma ou de outra forma, o avanço no debate, no sentido de permitir a estruturação desse campo disciplinar da sociologia das redes sociais, exige ampliar a noção de rede, de modo que se considerem igualmente válidas as dimensões objetivas e subjetivas, materiais e simbólicas. A integração das significações subjetivas na análise de redes exige, naturalmente, outras abordagens interpretativas mais complexas fenomenológicas e hermenêuticas - que são desconhecidas pela maior parte dos teóricos de redes. Essas últimas abordagens, assim como as entendemos, são mais adequadas para o conhecimento profundo do cotidiano nas sociedades complexas da atualidade. Ao colocar em relevo diferentes níveis de percepção da realidade humana, de variedade de entendimentos das linguagens socioculturais e de narrativas da vida cotidiana que estão sempre mescladas com apreciações lógicas e emoções incalculáveis -, revela-se toda a complexidade do real. E, sem discussão sobre o simbolismo, toda análise de redes permanece, de certo modo, superficial, já que são eliminadas as significações formadas pelas intersubjetividades que fundamentam a vida social.

Como assinala Lemieux, ao analisar os estudos sobre redes, pode-se perceber que houve um excesso de modelização, com prejuízo do entendimento das práticas dos atores envolvidos (Lemieux, 1999, p. 7). Para Granovetter, simpatizante da tese de corte racional, a responsabilidade seria das teorias de rede baseadas na análise estrutural, que teriam esvaziado os conteúdos, prejudicando o entendimento da complexidade das situações individuais. Ele reprova a análise estrutural pelo fato de ela perder-se nos detalhes das análises quantitativas de redes até o sectarismo (Granovetter, 2000, p. 35). De uma perspectiva contrária, os simpatizantes da análise estrutural criticam aqueles que acumulam dados descritivos sobre as trajetórias individuais sem nenhuma força explicativa, como seria o caso dos individualistas metodológicos e os de corte racional. Mas, esclarece Mercklé, essa propensão ao dedutivismo é comum tanto nos adeptos da análise estrutural, como naqueles de corte racional, conduzindo frequentemente a formas sociológicas particulares de raciocínio, nas quais o estatuto, de fato, aparece algumas vezes como secundário (Mercklé, 2004, p. 105). Como 
ambas as vertentes desvalorizam a dimensão intersubjetiva, por conseguinte as metodologias adotadas também carecem de valor como métodos orientados para a atenção a situações subjetivas, tais como histórias de vida, grupos focais, pesquisas participantes, entre outras.

Nesses anos em que viemos refletindo sobre o caráter e a aplicabilidade das redes, chegamos a constatar que a noção sofre, então, de uma indefinição crônica, produzida por suas múltiplas, contraditórias e superficiais leituras, o que compromete seu interesse prático para a compreensão da natureza, dos sentidos e dos rumos dos novos grupos emergentes e de suas identidades socioculturais. Na medida em que os elementos intersubjetivos não são considerados seriamente na discussão sobre hermenêutica das redes, o entendimento do que seja "racionalidade humana" se limita fatalmente a uma visão técnica, desumanizada e moralmente comprometida com o utilitarismo materialista e individualista. Por conseguinte, na maioria das vezes, a noção de redes serviu apenas para justificar, mediante lindos gráficos visuais e fórmulas de álgebra aparentemente complexas, opiniões banais sobre a vida social, que denotam pouca clareza científica e revelam um compromisso suspeito com as ideologias neoliberais. Essa é a herança do peso do utilitarismo no debate sobre redes sociais.

Seguindo a proposta de K. Wilber acerca de conceitos superficiais e profundos (Wilber, 2003), consideramos que aquelas leituras que apontam particularmente para a dinâmica utilitarista, funcional e individualista são rasas e conservadoras por construírem uma interpretação limitada da realidade. Aquelas outras que revelam o amplo elenco de determinações antiutilitaristas e que se preocupam em vincular a dinâmica relacional e não só os elementos objetivos e quantificáveis, mas, igualmente os motivos simbólicos e subjetivos da ação social, nós as denominamos de profundas e emancipadoras. As divergências entre ambas as tendências se devem basicamente ao fato de que um pensamento de simplificação que apenas dá conta de um aspecto da realidade-como é o caso das teorias funcionalistas e utilitaristas - não pode cobrir a totalidade sistêmica humana, que exige mapeamentos teóricos e metodológicos mais amplos e mais profundos do ponto de vista cognitivo, emocional, político, estético e moral.

\section{Alguns pontos para orientar o desenvolvimento do debate}

A discussão sobre as perspectivas paradigmáticas das redes sociais certamente não se esgota nos limites de um texto como este. Contudo, para estimular o debate, gostaria de registrar alguns pontos que nos parecem centrais nesta discussão.

1. Tanto as teorias de redes da análise estrutural como aquelas outras baseadas na visão racional e no individualismo metodológico compartilham um mesmo enfoque utilitarista, pragmático e unilateral, para explicar as racionalidades e interesses dos atores em situações sociais de grupo, privilegiando, para isso, as análises dedutivas, baseadas em modelos matemáticos e estatísticos. Mas tais métodos e técnicas não dão conta, de fato, da complexidade das práticas sociais. Por conseguinte, os estudos atuais de redes revelam a presença de um imbróglio de teorias - análise estrutural, funcionalismo, visão racional, individualismo metodológico, teorias de capital social, teoria de gráficos e álgebra linear - que se comunicam sem rigor teórico entre si. A hegemonia do utilitarismo, no campo científico, vem significando a ampliação das distâncias entre a pretendida novidade teórica, que seria dada pelas teorias de redes, e a pobreza das teorias estatísticas e matemáticas, acionadas para provar a validade empírica - por dedução - da pretendida racionalidade dos atores sociais nas redes. A análise das redes sociais permaneceu, então, mais como domínio privilegiado da formalização matemática e da simulação do que da investigação empírica, mais de dedução que da indução, mais da modelação que da interpretação (Mercklé, 2004, p. 104). Para fazer frente a 
sua insuficiência explicativa, os teóricos utilitaristas e individualistas vêm intensificando suas investigações em duas direções: uma delas, no plano teórico, apoiando-se nas teorias do capital social para realizar a tradução adaptativa necessária das teses individualistas aos fenômenos de rede; a outra, no plano metodológico, aproximando-se da engenharia de sistemas para incorporar modelos matemáticos, sob o suposto errôneo de que as ciências "exatas" podem cobrir, com suas teses positivistas, a incapacidade enfrentada pelo utilitarismo para explicar o caráter expressivo do cotidiano no mundo contemporâneo.

2. A aliança das teorias utilitaristas nas ciências sociais - representadas, sobretudo, pelo individualismo metodológico e pela "racional choice" - busca promover um novo campo teórico, o do Capital Social, que se supõe poderia aparecer como a síntese teórica máxima nos estudos sobre redes sociais. Tal ambição esconde uma operação ideológica dirigida para a sistematização de um pensamento único sobre as redes sociais nas ciências sociais. O Capital Social é o termo que designa o esforço de incluir teorias e autores simpatizantes do utilitarismo no amplo processo de colonização das novas manifestações sociais, políticas e culturais da sociedade civil organizada, que surgem no contexto do declínio dos antigos movimentos sociais, guardando um forte conteúdo anticapitalista. O prestígio adquirido por essas teorias emerge das tentativas de capturar e submeter significações subjetivas “anticapitalistas"-emocionais, afetivas, oníricas, estéticas, pulsionais - a esquemas cognitivos e racionalizantes. Assim, ao generalizar o interesse a todas as esferas da consciência - e da inconsciência - tais autores aparentam haver vencido a luta entre objetivistas e subjetivistas, provando que tudo é interesse e cálculo. Desse modo, temas como amor, confiança, amizade, memória, entre outros, passam a ser vistos como recursos que podem ser objeto de cálculo interessado, recursos do "capital".

3. Uma questão que nos parece obvia é que as teo- rias individualistas que estão na base dessa estratégia colonizadora são suficientemente abstratas para dar conta do contexto sociocultural e histórico do fenômeno das redes sociais. Daí a necessidade de um corpo teórico utilitarista que tenha uma missão colonizadora e que apareça na aparência - como um sistema explicativo amplo que englobe todas as esferas do conhecimento e da ação social, objetivas e subjetivas. Isto é, que se apresente como abarcando o conjunto de determinantes sociais, culturais e históricos das redes, não com o fim de promover uma compreensão hermenêutica e solidária das redes, mas de capturar tais recursos coletivos com a finalidade de legitimar a visão monolítica, de corte individual e egoísta. Desse modo, essas teorias se adéquam perfeitamente como dispositivos de tradução da moral individualista na normalização e privatização de uma ideia generosa, como a das redes sociais. As redes que, originalmente, são construtos históricos e hermenêuticos que se filiam aos desdobramentos das experiências sociais e políticas de grupos atuantes, são reduzidas pelo utilitarismo a meros artifícios de análise, com objetivos de controle autoritário da prática social e da esfera pública. As teorias do capital social maquilam os fundamentos intersubjetivos da vida social memórias, valores, sentimentos etc. - com o fim justamente de negar sua existência como fatores independentes dos elementos racionalizadores e objetivantes.

4. Outro ponto a ser registrado é que a adoção de tais teorias na investigação sociológica não é um ato ideologicamente neutro. Elas constituem peças de um quebra-cabeças chamado network analysis, que se popularizou razoavelmente em âmbito mundial. A ideia de tal análise reflete o esforço mais exitoso das ditas teorias: o desaparecimento da dimensão fenomênica e comunocêntrica das redes sociais em favor da construção de um dispositivo instrumental, egocêntrico e fictício, orientado para a colonização dos processos sociais coletivos. O network analysis tem a função de completar o enunciado 
de cientificidade pretendido pelos intelectuais utilitaristas, com vistas a completar o trabalho de colonização da sociologia, controlando manifestações sociais e culturais que podem ameaçar as bases do pensamento monolítico (que é articulado, por sua vez, com a dominação capitalista mais geral). Assim, essas teses neopositivistas contribuem inevitavelmente para estabelecer uma distância hierárquica e moral importante entre o observador científico externo e o observado. Reavivam o tradicional dualismo metodológico de inspiração cartesiana, pelo qual o sujeito e o objeto são fenômenos estranhos entre si, com propósitos que têm menos um interesse científico e mais um objetivo ideológico. Criam uma distância fictícia que é politicamente conveniente para que o sujeito colonizador na ciência possa controlar, a uma distância segura, o objeto de análise, a saber, os sistemas de solidariedade humanos, para poder melhor organizar o discurso utilitarista sobre a "verdade". Segundo A. Gouldner, semelhante dualismo - entre observador e observado - significa a traição dos objetivos mais fundamentais de toda a sociologia. Ele tem implicações normativas resultantes da interação entre sujeito e objeto que não podem ser subestimadas (Gouldner, 1989, p. 23). De fato, na medida em que o dualismo reforça os mecanismos de controle das elites tecnocratas - e assim, indiretamente, das elites capitalistas - inibe o surgimento de novas possibilidades de construção do conhecimento que sejam dialógicas e plurais, comprometidas com outro conhecimento produzido diretamente na experiência vivida, coletiva e intersubjetivamente pelos atores sociais.

5. Por conseguinte, cabe aqui muito bem a consideração de K. Wilber de que esses entendimentos de redes são restritivos e superficiais, por explicarem somente o lado visível das coisas observadas, o ISTO, sem incluir os elementos culturais, morais e psicológicos presentes nas redes, que constituem as dimensões do EU e do NÓS da ação social (Wilber, 2006). Pensamos igualmente que, além de superficiais, são conservadores, pois privilegiam uma compreensão egocêntrica da realidade, em detrimento de visões comunitariocêntricas ou cosmocêntricas, que permitiriam um entendimento generoso e solidário da totalidade da vida social. ${ }^{16}$ Se a sociologia das redes sociais fosse capaz de minimizar o peso do método explicativo e dedutivo, organizado em torno da narrativa da network analysis, a favor de metodologias compreensivas e interpretativas mais complexas e capazes de superar tal dualismo metodológico, veríamos, como resultado imediato, o observador científico sair de sua posição de neutralidade para aproximarse do objeto. Assumindo o papel de "protagonista" em um jogo em que a "significação da ação dos outros e, em primeiro lugar, a trama da interação que o autor estabelece consigo mesmo ainda que isso se faça com certo distanciamento" (Freitag, 1989) -, o observador se vê implicado moralmente com a construção social compreensiva da realidade. A posição de protagonista leva o observador a buscar estabelecer uma mediação significativa comum com o objeto, a qual se materializa por certos procedimentos técnicos facilitadores da interlocução, como a descrição, o relato, a imagem, a atenção que, agregamos, se tornam efetivos por técnicas que favorecem a aproximação entre as partes, como aquelas dos grupos focais e das entrevistas em profundidade.

Por fim, o problema central dessas teses sobre a análise de redes é que elas veem apenas o fluxo social por uma lente ambivalente - indivíduo e estrutura - que têm como eixo comum o interesse egoísta. Tais teses pecam por um aspecto crucial, já inscrito em sua própria denominação, ou seja, se inspiram na óptica da privatização de um conjunto de recursos materiais e funcionais por certos agentes, sem considerar que tais recursos, como a confiança, por exemplo, existem apenas a partir de um contexto intersubjetivo - emo-

${ }^{16}$ De fato, o uso convencional e superficial de rede é muito insatisfatório quando se propõe a estudar sistemas complexos e interativos como os sistemas vivos e humanos. Por isso, Morin critica os paradigmas da simplificação, baseados nessa visão mecânica e funcional do ser humano, para propor um paradigma de complexidade eu dê conta dos mecanismos de reprodução inteligente dos sistemas vivos e de sua interatividade criativa com outros ambientes externos (Morin, 1990). 
cional, imaginativo, representacional - que não pode ser reduzido a um recurso de mobilização estratégica, um "capital”, como dizem seus adeptos. As leituras conservadoras e superficiais de redes, defendidas pelo pensamento hegemônico, tendem a privilegiar metodologias quantitativas, crendo, ilusoriamente, que a realidade se fundamenta em leis positivas mensuráveis. Apoiam-se, principalmente, como nos recorda P. Mercklé, na teoria dos gráficos e na aplicação da álgebra linear a dados relacionais (2004, p. 22), com o propósito de medir as propriedades estruturais e as leis fixas das redes. Assim, a crescente aceitação da teoria dos gráficos e da álgebra linear na análise de dados relacionais é diretamente proporcional ao esquecimento, por parte da sociologia, das dimensões normativas e reflexivas da prática social.

Contudo, tal vitória de Pirro não tem grande impulso, e a realidade - como sempre o faz obriga o pensamento simplificador a submeter-se a sua complexidade dialógica. Como diriam os sábios taoístas, quanto mais se olha o dia, mais a noite se torna exuberante, quanto mais se deseja o efeito solar, mas se prolonga a chuva, quanto mais se deseja controlar a realidade externa, mais o mundo interno se torna um pesadelo.

Tendo em mente essas considerações gerais, nossa hipótese é a de que as teorias do capital social, ao intentar adequar as teses utilitaristas a algo que não é apenas uma noção conceitual, mas um fenômeno sócio-histórico - a tendência de formação de grupos associativos de pequeno e médio porte no interior do mundo da vida em sociedades complexas - tornam-se prisioneiras de uma contradição insuperável. Tal contradição tem dois aspectos: um deles, a simplicidade do corpo teórico-metodológico utilitarista para explicar fenômenos sócio-históricos complexos como o das redes; o outro, o de que os grupos oprimidos e os intelectuais não-hegemônicos, dentro e fora da academia, resistam a submeter-se a essa hierarquia que - se aceita - quebra a dimensão associativa generosa, presente na ontologia das redes sociais nas sociedades complexas.

O caminho da sistematização das redes sociais como um novo paradigma sociológico passa, assim, por esse esforço de desnaturalização de noções da moda e, principalmente, pela busca de demonstrar que as ideias "científicas" não são neutras. Trata-se de mostrar que tais noções estão relacionadas com certo pensamento moderno e utilitarista que teve uma missão colonizadora importante para a formação de públicos usuários acadêmicos e não-acadêmicos cativos. Contra esse esquecimento da relação entre ciência e poder nas ciências sociais, cabem reações que contribuam para desvelar a trama colonizadora, revelando outras possibilidades de articulação do saber científico e do saber comum, em torno da promoção de uma sociologia mais reflexiva, interiorizada, interativa e orientada para um entendimento mais generoso das novas mobilizações sociais e culturais. Isso, tratando-se de América Latina, tem um valor especial.

Para nós, a base do novo paradigma sociológico de redes sociais já está legitimada pelas novas mudanças históricas, pelas novas teorizações sobre as modalidades de existência dos movimentos sociais como redes, como bem afirma Melluci. Essas bases estão fixadas, sobretudo, pelas novas teorias pós-coloniais, como as de Bhabha (2003) ou de Hall (2006), que contribuem para denunciar os aspectos políticos do pensamento colonizador, ao mesmo tempo em que valorizam as diferenças culturais e a emergência de novas identidades minoritárias. Seguramente, a evidência organizacional do novo paradigma de redes, conectada com o novo paradigma associativo nas ciências sociais, que éo dom, como explica Caillé (2000), não se traduz automaticamente em novas teses universitárias. Ainda há um caminho a seguir na divulgação institucional e organizacional do novo paradigma, de modo que ele possa influenciar mais claramente as teses acadêmicas. Mas o problema maior nos parece que já foi resolvido, a saber, o de demonstrar a insuficiência das teses colonizadoras para explicar "cientificamente" a complexidade dos movimentos sociais contemporâneos, sobretudo aqueles reterritorializados e referentes a minorias ativas.

(Recebido para publicação em junho de 2010) (Aceito em agosto de 2010) 


\section{REFERÊNCIAS}

ABRAMOVAY, R. A rede, os nós, as teias: tecnologias alternativas na agricultura. Revista de Administração Pública, Rio de Janeiro, v.34, n.6, p.159-177, 2000.

ADLER-LOMNITZ, L. Redes sociales, cultura y poder Ensayos de antropología latinoamericana. México: Migue Ángel Porrúa, 1994.

ALONSO DAVILA, I. Nada de soledades: algunas notas sobre redes sociales entre mujeres. El casco antiguo de Alicante. Canelobre: Revista del Instituto Alicantino de Cultura, Alicante,ES, n.23/24, p.199-208, 1992.

ARNOLD-CHATALIFAUD, M.; THUMALA, D.; URQUIZA, A. Colaboración, cultura y desarrollo: entre el individualismo y la solidariedad organizada. In:

(Org.) Colaboración, cultura y desarrollo. Santiago: Universidad del Chile/Fundacion Sóles, 2007. p.15-34.

BARNES, J. Class and comittees in a norwegian island parish. Human Relations, London, n.7, p.39-58, 1954.

BHABHA, H. O local da cultura. Belo Horizonte: UFMG, 2003. BOURDIEU, P. Las formas de capital. Lima: Piedra Azul, 1999.

BOTT, E. Família e rede social. Rio de Janeiro: Livraria Francisco Alves, 1976

CAILLÉ, A. Critique de la raison utilitaire: Manifeste du MAUSS. Paris: La Découverte, 1989

. Anthropologie du don: le tires paradigma Paris Desclée de Brouwer, 2000.

CALLON, M. La science et ses réseaux. Gènese et circulation des faits scientifiques. Paris: La Découverte; Conseil de l"Europe;UNESCO, 1989.

CANALS, J. Comunidad y redes sociales: de las metáforas a los conceptos operativos. Revista de Servicios Sociales Política Social, Bogotá, n.23, p.7-18, 1991.

CASTELLS, M. A sociedade em redes. São Paulo: Paz e Terra, 2007.

COLEMAN, J. Foundations of social theory. Cambridge: Harvard University, 1990

DERRIDA, J. L'écriture et la différence. Paris: Seuil, 1967. ELIAS, N. A sociedade dos indivíduos. Rio: Jorge Zahar, 1994

FLEURY, S.; DUVERNEY, A.M. Gestão de redes: a estratégia de regionalização da política de saúde. Rio de Janeiro: Ed. FGV, 2007.

FONTES, B. Capital social e terceiro setor. Sobre a estruturação de redes sociais em associações voluntárias. In: MARTINS, P. H.; FONTES, B. Redes sociais e saúde novas possibilidades teóricas. Recife: Ed. UFPE, 2004.

OCAULT, M. A arqueologia do saber. Rio de Janeiro: Forense Universitária, 2007.

FREITAG, M. Las sciences sociales contemporaines et le problème de la normativité. Revue du Mauss, Paris, La Découverte, n.4, p.26-38, 1989.

GIL, J.; SCHMIDT, S. Análisis de redes. Aplicaciones a las ciencias sociales. México: IIMAS-UNAM, 2002.

GODBOUT, J. O espírito da dádiva. Rio de Janeiro: Fundação Getúlio Vargas, 1999.

GOHN, M.G. Movimentos sociais no início do século XXI: antigos e novos actores. Petrópolis: Vozes, 2003.

GOULDNER, A. Pour une sociologie réflexive. Revue $d u$ Mauss, Paris, La Découverte, n.4, p.11-25, trimestrielle, 1989.
GRANOVETTER, M. The strenght of weak ties: a network theory revisited. Sociological Theory, Hoboken, WileyBlackwell, v.1, p.201-233, 1983.

Le marché autrement. Paris: Desclée de Brouwer, 2000.

HALL, S. Da diáspora: identidades e mediações culturais. Belo Horizonte: Ed. UFMG, 2003.

HERRERO, R. La terminología del análisis de redes. Problemas de definición y de traducción. Politica y Sociedad, Madrid, n.33, p.131-148, 2000.

KUHN, T. A estrutura das revoluções científicas. São Paulo: Perspectiva, 1975

LACERDA, A.; PINHEIRO, R.; GUIZARDI, F.L. Espaço público e saúde: a dádiva como constituinte de redes participativas de inclusão social. In: MARTINS, P. H.; CAMPOS, R. (Org.) Polifonia do dom. Recife: Ed. da UFPE, 2006. p.311-332

LATOUR, B. Reassembling le social. An introduction to ActorNetwork-Theor. Oxford: Oxford University Press, 2005.

LEINHART, S. Social networks. A developing paradigm. New York: Academic Press, 1977.

LEMIEUX, V. Les coalitions, liens, transactions, contrôles. Paris: PUF, 1999

LIN, N. Social capital: a theory of social structure and action. Cambridge: Cambridge University Press, 2001.

MACÍAS, A.G. Redes sociales y clusters empresariales. REDES - revista hispana para el análisis de redes sociales, Barcelona, v.1, n.6, enero, p.1-20, 2002.

MADARIAGA, C.; ABELLO LLANOS, R.; SIERRA GARCÍA, O. Redes sociales, infancia, familia y comunidad. Barranquilla,CO: Universidad del Norte, 2005.

MANCE, E. A revolução das redes. A colaboração solidária como uma alternativa pós-capitalista à globalização atual, 2.ed.. Petrópolis: Vozes, 2001.

MARTINS, P.H. Contra a desumanização da medicina: crítica sociológica das práticas médicas modernas. Petrópolis: Vozes, 2003.

As redes sociais, o sistema da dádiva e o paradoxo sociológico In: ; FONTES, B. Redes sociais e saúde: novas possibilidades teóricas. Recife: Ed. UFPE, 2004 p. 21-48.

Ação pública, redes e arranjos familiares. In: FONTES, B.; MARTINS, P.H. (Org.) Redes, prática associativas e gestão pública em saúde. Recife: Ed. UFPE 2006. p.19-50;

De Lévi-Strauss a MAUSS - Movimento AntiUtilitarista nas Ciências Sociais: itinerários do dom. Revista Brasileira de Ciências Sociais. São Paulo, ANPOCS, v.23, n.66, p.105-129, 2008

MARQUES, E. C. Estado e redes sociais: permeabilidade e coesão social nas políticas urbanas no Rio de Janeiro. São Paulo: FAPESP; R Evan, 2002.

MATO, D. Redes de "thinks tanks", fundaciones, empresarios, dirigentes sociales, economistas, periodistas y otros profesionales en la promoción de ideas (neo)liberales a escala mundial.In: (Coord.) Políticas de economía, ambiente y sociedad en tiempos de globalización. Caracas: Facultad de Ciencias Económicas y Sociales, Universidad Central de Venezuela, 2005. p.131153.

Importancia de los referentes territoriales en procesos transnacionales. Una crítica de la idea de "desterritorialización" basada en estudios de casos Estudios de Sociología, Araraquara,SP, v.12, n.23, p.3563, 2007. 
MAUSS, M. Ensaio sobre a dádiva: forma e razão da troca nas sociedades arcaicas In: Sociologia e Antropologia. São Paulo: Cosac \& Naify, 2003. p.185-314

MELlUCI, A. A invenção do presente. Petrópolis: Vozes, 2001

MERCKLE, P. Sociologie des réseaux sociaux. Paris: La Découverte, 2004.

MERLEAU-PONTY, M. Conversas, 1948. São Paulo: Martins Fontes, 2004.

MOLINA, J. L. Análisis de redes y cultura organizativa: una propuesta metodológica. Revista Española de Investigaciones Sociológicas, Madri, n.71/72, p.249-263, 1995.

MOREIRA, M. Dádiva, reciprocidade e associação em rede na área da saúde In: MARTINS, P. H.; CAMPOS, R. (Org.) Polifonia do dom. Recife: Ed. UFPE, 2006. p.285-310.

MORENO, J. Psychothérapie de groupe et psychodrame. Paris: Quadrige ;Presses Universitaires de France, 1987.

MORIN, E. Introduction à la pensée complexe, Paris: ESF Editeur, 1990

MUSSO, P. Critique des réseaux. Paris: PUF, 2003.

OSORIO, F. Desde dónde se escriben las ciencias socials al comienzo del siglo XXI. In: (Ed.) Epistemología de las ciencias sociales: $\overline{\text { breve }}$ manual. Santiago: Ediciones Universidad Catolica Silvia Henríquez, 2007.

PIZARRO, N. Regularidad relacional, redes de lugares y reproducción social. Política Y Sociedad, Madrid, n.33, p.167-198, 2000.

PORTUGAL, S. Contributos para uma discussão do conceito de rede na teoria sociológica. Oficina do CES: publicação seriada do Centro de Estudos Sociais. Coimbra,PT, Universidade de Coimbra, n.271, 2007
PUTNAM, R. Comunidade e democracia: a experiência da Itália moderna. 3.ed. Rio de Janeiro: Fundação Getúlio Vargas, 2002.

REQUENA SANTOS, F. Redes sociales y mercado de trabajo. Elementos para una teoría del capital relacional. Madrid: Centro de Investigaciones Sociológicas \& Siglo XX, 1991. (Col. monografías, n.19)

Redes de amistad, felicidad y familia. Revista Española de Investigaciones Sociológicas. Madrid, n.66, p.73-89, 1994.

RODRÍGUEZ, J. A. Análisis estructural y de redes Madrid: Ed. Centro de Investigaciones Sociológicas \& Siglo XXI, 1995

SANTOS, B. S. Introdução a uma ciência pós-moderna. Rio de Janeiro: Graal, 1989.

SCHERER-WARREN, I. Redes sociais: trajetórias e fronteiras In: DIAS, L.C.; SILVEIRA, L.L. (Org.) Redes, sociedades e territórios. Santa Cruz do Sul: EDUNISC, 2005 p.29-50.

SCRIBANO, A. La investigación social cualitativa. Buenos Aires: Prometeo Libros, 2008.

SIMMEL, G. Sociologie: etudes sur les formes de socialisation. Paris: PUF, 1999.

TAYLOR, C. As fontes do self: a construção da identidade moderna. São Paulo: Edições Loyola, 2005.

VILLASANTE, T. Redes e alternativas. Estratégias e estilos criativos na complexidade social. Petrópolis: Vozes, 2002 .

WILBER, K. Uma breve história do universo: de Buda a Freud. 3.ed. Rio de Janeiro: Nova Era, 2006.

WOLFE, A. The rise of network thinking in anthropology. Social Networks, [S.l.], v.1, p. 53-64, 1978. 


\section{SOCIAL NETWORKS AS NEW INTERPRETATIVE MARKERS OF CONTEMPORARY COLLECTIVE MOBILIZATIONS}

\author{
Paulo Henrique Martins
}

The direction of social movements and social and cultural mobilizations in contemporaneity point out the weakening of the old theoretical positivist markers who subordinated the constitution of identity practices to certain reductionist criteria, such as economic utilitarianism and progress ideology. However, recent changes produced by the processes of disterritorialization and reterritorialization in complex societies require new types of actors, conflicts and mediation, and networks are an examplary social form of such changes. But the networks are not automatically imposed as a new interpretative marker. It is important to explain that they are the object of struggle in the intellectual field and can meet various readings, both utilitarian and anti-utilitarian.

Keywords: social networks, social movements, utilitarianism, sociological theory.

\section{LES RÉSEAUX SOCIAUX COMME RÉFÉRENCE INTERPRÉTATIVE DES MOBILISATIONS COLLECTIVES CONTEMPORAINES}

\author{
Paulo Henrique Martins
}

Les directions que prennent les mouvements sociaux et les mobilisations sociales et culturelles contemporaines montrent bien l'appauvrissement des anciennes références théoriques positivistes qui subordonnaient la constitution des pratiques identitaires à certains critères réductionnistes tels que ceux de l'utilitarisme économique et de l'idéologie du progrès. Toutefois, les récents changements dus au processus de déterritorialisation et de reterritorialisation dans les sociétés complexes imposent de nouveaux types d'acteurs, de conflits et de médiations, les réseaux constituant un exemple social de ces changements. Mais les réseaux ne s'imposent pas automatiquement comme nouvelle référence interprétative. Il est important d'expliquer qu'ils sont l'objet de controverses dans le champ intellectuel et qu'ils peuvent être sujets à différentes lectures, à la fois utilitaires et antiutilitaristes.

Mots-CLÉS: réseaux sociaux, mouvements sociaux, utilitarisme, théorie sociologique.

Paulo Henrique Martins - Professor Titular do Departamento de Ciencias Sociais da UFPE (Universidade Federal de Pernambuco). Doutor em Sociologia pela Universidade de Paris I. Pós-doutoramento na Universidade de Nanterre, Paris X. Pesquisador Visitante do London School of Politics and Economics Science. Pesquisador I do CNPq, coordenador do Núcleo de Cidadania (NUCEM) da UFPE. Vice-presidente da ALAS (Associação Latinoamericana de Sociologia). Participa também do MAUSS (Movimento Antiutilitarista nas Ciências Sociais), que edita a Revue du Mauss. Membro dos Conselhos Editoriais das revistas: Revue Culture et Société (Strasbourg - França), Política \& Trabalho (Paraiba), Revista de Sociologia Política (Santa Catarina), Estudos de Sociologia (Pernambuco). Na sua atividade intelectual busca articular de forma interdisciplinar os estudos sobre a dádiva, buscando dialógo permanente com a antropologia, com a política e com a psicologia; seus estudos em Teoria Social, Sociologia da Saúde e Sociologia do Poder revelam frequentemente os seguintes indicadores: dádiva, cidadania, democracia, solidariedade, políticas públicas, saúde e cultura. 